\title{
Penerapan Budaya 5S sebagai Penguatan Pendidikan Karakter Siswa di MTs Muhammadiyah 9 Mondokan, Sragen
}

\author{
Yulianto Bambang Setyadi ${ }^{1}$, Tri Oktafia Anggrahini ${ }^{2}$, Nanda Putri Kusuma Wardani ${ }^{3}$, Wakhid \\ Nanang Yunanto ${ }^{4}$, Oktadina Tri Setiawati ${ }^{5}$, Ganjar Nur Hidayati ${ }^{6}$, Gita Ristiani Amalia ${ }^{7}$, Meilinda \\ Kurnia Dewi ${ }^{8}$, Nugroho Priyatmojo ${ }^{9}$, Ismiyanto Nugroho ${ }^{10}$ \\ 1,2,3,4,5,6,7,8,9,10 Fakultas Keguruan dan Ilmu Pendidikan, Universitas Muhammadiyah Surakarta, \\ Indonesia
}

\section{INFORMASI ARTIKEL}

Histori Artikel:

Submit: 27 April 2020

Revisi: 2 Mei 2020

Diterima: 4 Mei 2020

Publikasi: 6 Mei 2020

Periode Terbit: Desember 2019

\section{Kata Kunci: \\ pendidikan \\ pendidikan karakter, \\ program $5 \mathrm{~s}$, religius, \\ bersahabat/komunikatif,}

peduli sosial

\section{Correspondent Author:}

Tri Oktafia Anggrahini

Fakultas Keguruan dan Ilmu Pendidikan

Universitas Muhammadiyah Surakarta,

Indonesia

Email:

trioktafiaanggrahini@gmail.com

\begin{abstract}
ABSTRAK
Pendidikan karakter sangat penting dalam membentuk perilaku peserta didik khususnya anak-anak dan remaja yang sangat dipengaruhi oleh dampak negatif perkembangan zaman. Pendidikan karakter yang paling dasar ditanamankan sejak dini khususnnya di bangku sekolah adalah budaya 5S (Salam, Senyum, Sapa, Sopan, Santun). Kegiatan ini bertujuan untuk menguatkan pendidikan karakter siswa di MTs Muhammadiyah 9 Mondokan, Sragen. Dengan adanya program 5S (Salam, Senyum, Sapa, Sopan, dan Santun) ini dapat disimpulkan bahwa kegiatan berlangsung dengan efektif dan tepat sasaran, apabila seluruh warga sekolah saling memiliki sikap peduli akan pendidikan karakter. Sehingga Tidak hanya siswa yang wajib berperilaku baik, tetapi guru sebagai salah satu faktor pendukung juga harus mampu menjadi suri tauladan bagi siswanya. Kegiatan 5S (Salam, Senyum, Sapa, Sopan, dan Santun) paling tidak mencerminkan pengembangan karakter religius, bersahabat atau komunikatif, dan peduli sosial. Kesemuanya ini akan lebih baik jika dilakukan secara rutin dan berkelanjutan.
\end{abstract}

\section{Pendahuluan}

Perkembangan zaman yang semakin maju mempengaruhi kehidupan sosial dan budaya masyarakat, perkembangan ini ditandai dengan banyaknya alat komunikasi yang semakin canggih dan alat transportasi yang semakin efisien dan praktis. Selain dampak positif dari perubahan tersebut, perubahan zaman yang semakin pesat juga menimbulkan dampak negatif yang lebih banyak, sehingga perubahan yang terjadi bisa dikatakan tidak seimbang.

Salah satu contoh umum yang sering ditemukan yaitu penggunaan Hand Phone (HP).
Faktanya dengan adanya Hand Phone (HP) dapat memudahkan manusia dalam berkomunikasi jarak jauh, mencari informasi, dan sebagai sarana hiburan. Terlepas dari manfaat Hand Phone (HP) tersebut, terdapat banyak dampak negatif yang ditimbulkan antara lain informasi dapat menyebar dengan cepat, sehingga berita yang tersebar belum tentu terbukti kebebenarannya, maraknya situs pornografi yang diakibatkan mudahnya mengakses internet, dan kecanduan terhadap Hand Phone (HP) khususnya game online bagi anak-anak dan remaja, dimana hal ini 
mengakibatkan timbul sifat kurang peduli terhadap sesama dan lingkungan sekitar sehingga pendidikan karakter yang dimiliki oleh anak-anak zaman sekarang tergolong rendah.

Sekolah menjadi salah satu tempat bagi siswa dalam memperoleh pendidikan karakter. Pendidikan karakter adalah cara berpikir, bersikap, dan berperilaku yang menjadi sebuah karakteristik setiap orang untuk melangsungkan hidupnya dan bekerja sama antarindividu lainnya di dalam lingkungan keluarga maupun masyarakat (Suyanto, 2009). Sedangkan menurut (Kertajaya, 2010) pendidikan karakter adalah sebuah karakteristik atau kepribadian yang dimiliki oleh setiap individu.

(Koesoema, 2010) mengutarakan bahwa pendidikan karakter merupakan struktur antropologis setiap individu dimana karakter bukan hanya sekedar tindakan saja, tetapi juga merupakan suatu hasil dan proses. Maka dari itu, setiap individu diharapkan dapat bertanggung jawab atas tindakan yang telah diperbuat. Selain itu, pendidikan karakter juga merupakan suatu proses atau wadah yang mempunyai sistematika untuk menanamkan nilai-nilai karakter yang meliputi pengetahuan, kesadaran, serta tindakan (Prasetyo \& Rivasintha, 2015).

Berdasarkan pemaparan para ahli tersebut, maka dapat disimpulkan bahwa pendidikan karakter adalah sifat atau perilaku yang harus dimiliki siswa mulai dari pengetahuan mengenai mana yang baik dan pantas, kesadaran akan sesama manusia hingga makhluk hidup lain, serta tindakan sebagai implementasi dari pengatuhan dan kesadaran yang telah ada (Thambu, N., et al, 2020).

Kementerian Pendidikan dan Kebudayaan Indonesia merumuskan 18 nilai-nilai yang perlu dikembangkan melalui pendidikan karakter, agar peserta didik memiliki watak dan perilaku baik, diantaranya yaitu: (1) religius, (2) jujur, (3) toleransi, (4) disiplin, (5) kerja keras. (6) kreatif, (7) mandiri, (8) demokratis, (9) rasa ingin tahu, (10) semangat kebangsaan, (11) cinta tanah air, (12) menghargai prestasi, (13) bersahabat, (14) cinta damai, (15) gemar membaca, (16) peduli lingkungan, (17) peduli sosial, dan (18) tanggung jawab (Budhiman, 2017).

Pendidikan karakter merupakan proses pembudayaan dan pemberdayaan nilai-nilai luhur dalam lingkungan satuan pendidikan (sekolah), keluarga, dan masyarakat. Pendidikan karakter menjadi salah satu prioritas pembangunan nasional yang diamanatkan dalam Pancasila, Pembukaan UUD 1945, dan untuk mengatasi permasalah yang ada di Indonesia saat ini. Pendidikan karakter menanamkan kebiasaan, sehingga siswa dapat memahami (kognitif) tentang mana yang benar dan mana yang salah, mampu merasakan (afektif) nilai yang baik dan dapat dilakukannya (Gunawan, 2012:24-25).

Kerangka proses grand design pendidikan karakter memiliki strategi pengembangan yang dilihat dari dua konteks, yaitu mikro dan makro. Strategi pengembangan karakter pada konteks makro bersifat nasional mencakup keseluruhan perencanaan hingga evaluasi hasil yang merupakan tanggung jawab bersama serta melibatkan seluruh elemen pemangku kepentingan pendidikan nasional. Proses pengembangan karakter secara makro dibangun melalui pendekatan intervensi dan habituasi. Proses intervensi dilakukan secara formal dalam kegiatan pembelajaran yang terstruktur untuk mencapai tujuan pembentukan karakter. Proses 
Habituasi meliputi pembiasaan di dalam lingkungan keluarga dan masyarakat sebagai bentuk penguatan serta pembudayaan karakter (Citrapujiyati, 2017).

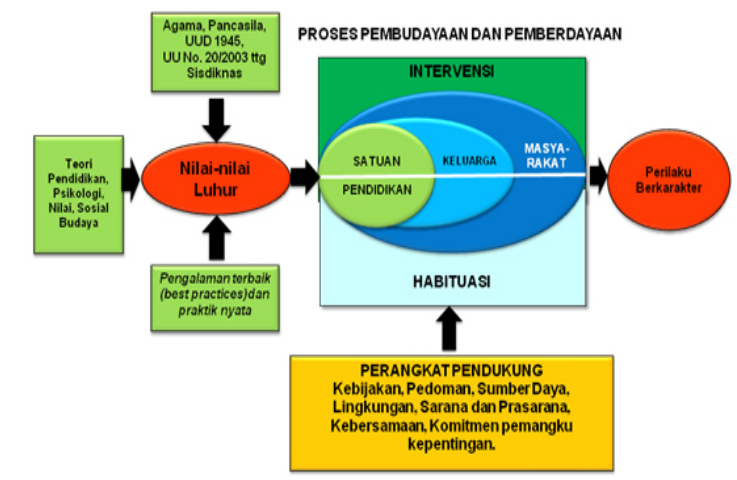

Gambar 1. Konteks Makro Pendidikan Karakter (Sumber: https://www.kemdikbud.go.id/)

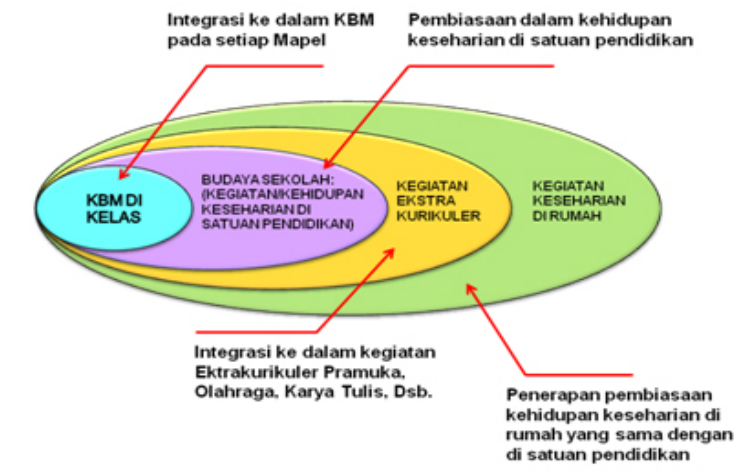

Gambar 2. Konteks Mikro Pendidikan Karakter (Sumber: https://www.kemdikbud.go.id/)

Strategi pengembangan karakter pada konteks mikro berlangsung pada satuan pendidikan yang utuh dan berupaya memberdayakan seluruh lingkungan belajar untuk menguatkan dan menyempurnakan pendidikan karakter. Secara mikro pengembangan karakter dapat dibagi dalam empat proses integrasi, yaitu: kegiatan belajar mengajar di dalam kelas, aktivitas belajar dalam budaya sekolah (school culture), ekstrakurikuler, dan aktivitas seharihari. Kegiatan pembelajaran di kelas agar dapat mengembangkan karakter dilaksanakan dengan menggunakan pendekatan terintegrasi dalam semua mata pelajaran (Samani dan Hariyanto, 2011:113).

Menurut Rusdianti (2015), ada beberapa komponen yang perlu diperhatikan dalam rangka menjalankan pendidikan karakter yaitu: partisipasi masyarakat, kebijakan pendidikan, kesepakatan, kurikulum terpadu, pengalaman pembelajaran, evaluasi, bantan orang tua, pengembangan staf, serta program pendidikan karakter yang harus dipertahankan dan diperbaharui melalui pelaksanaan dengan perhatian khusus pada tingkat komitmen tinggi.

Pendidikan karakter yang paling dasar di tanamankan sejak dini khususnnya di bangku sekolah adalah budaya 5S (Salam, Senyum, Sapa, Sopan, Santun). Salam dalam hal ini dapat dilakukan dengan cara berjabat tangan dan mengucapkan salam menurut agama dan kepercayaam masing-masing. Senyum adalah suatu ekspresi raut muka yang menggambarkan keramahan serta ketulisan hati untuk mencairkan suasana yang kaku. Sapa merupakan suatu tindakan untuk saling menghargai sesama manusia berupa tegur sapa. Sopan merupakan perilaku hormat yang ditunjukan terhadap orang lain. Santun adalah baik dan halus dalam hal tutur kata dan tindakan. Dari pengertian diatas, 5S dapat dijadikan sebagai suatu program penguatan pendidikan karakter siswa khususnya di MTs Muhammadiyah 9 Mondokan.

Berdasarkan permasalahan diatas kami selaku mahasiswa KKN-Dik di MTs Muhammadiyah 9 Mondokan akan menerapkan program 5S (Salam, Senyum, Sapa, Sopan, Santun) kepada siswa. Kegiatan ini bertujuan untuk menguatkan pendidikan karakter siswa di MTs Muhammadiyah 9 Mondokan, Sragen. 
Santun) untuk seluruh warga sekolah dapat

\section{Metode Pelaksanaan}

Pengabdian ini menggunakan metode studi literatur. Metode studi literatur yang dilakukan yaitu dengan menganalisis suatu permasalahan yang ditemukan dengan solusi berdasarkan pustaka atau literasi lainnya yang berkaitan dengan peran 5S (Salam, Senyum, Sapa, Sopan, dan Santun) sebagai progam untuk menguatkan pendidikan karakter siswa. Teknik pengumpulan data dengan cara observasi, wawancara, dan dokumentasi.

\section{Hasil Pelaksanaan dan Pembahasan}

Pada era globalisasi yang semikin pesat ini penguatan pendidikan karakter siswa sangat penting untuk dilakukan karena perilaku terpuji siswa telah mulai luntur. Maka dari itu, dalam pengabdian ini akan diterapkan program $5 \mathrm{~S}$ (Salam, Senyum, Sapa, Sopan, dan Santun) di MTs Muhammadiyah 9 Mondokan diharapkan dapat menguatkan karakter siswa. Beberapa upaya yang mendukung kegiatan ini anara lain observasi, sosialisasi, dan merealisasikan program.

Pertama, kegiatan observasi yang dilakukan dengan cara pengamatan secara langsung terhadap perilaku siswa dilingkungan sekolah. Dari hasil pengamatan yang telah dilakukan didapatkan bahwa perilaku yang ditunjukan tergolongan dalam nilai karakter yang rendah. Hal ini dilihat dari sikap siswa saat bertemu dengan guru kurang menunjukan perilaku sopan santunnya.

Berdasarkan kegiatan observasi inilah kami mencetuskan program 5S (Salam, Senyum, Sapa, Sopan, dan Santun) sebagai solusi untuk memperbaiki perilaku siswa agar lebih berkarakter. Menurut (Faozah, 2014) penerapan program 5S (Salam, Senyum, Sapa, Sopan, dan menguatkan karakter dan menjadikan semua warga sekolah memiliki kepribadian yang baik. Program 5S (Salam, Senyum, Sapa, Sopan, dan Santun) mengajarkan siswa bersikap saling menghormati satu sama lain.

Kedua, setelah kegiatan observasi dilaksanakan dan ditemukannya solusi dari permasalahan yang ada, kami melanjutkan dengan kegiatan sosialisasi mengenai program 5S (Salam, Senyum, Sapa, Sopan, dan Santun) kepada seluruh siswa di MTs Muhammadiyah 9 Mondokan. Sosialisasi dilakukan dengan memberikan pergertian tentang 5S (Salam, Senyum, Sapa, Sopan, dan Santun) dan juga mencontohkannya secara langsung.

Setelah diberikan pengertian, siswa juga diminta untuk mempraktekkan secara langsung bagaimana bersikap yang baik berdasarkan program 5S (Salam, Senyum, Sapa, Sopan, dan Santun) yang telah dikenalkan. Selain itu, dalam kegiatan sosialisasi ini disampaikan bagaimana pentingnya bersikap saling menghargai, simpati, dan empati di lingkungan sekolah maupun masyarakat.

Indonesia mengacu pada empat pilar pendidikan yaitu learning to know, learning to do, learning to be, learning to live together. Dari empat pilar tersebut diharapkan siswa mampu memahami hal baik yang harus dilakukan dan hal buruk yang harus dihindari serta memahami arti hidup diri sendiri dan orang lain, sehingga dapat saling menghargai untuk menciptakan lingkungan yang aman dan tentram di sekolahan. 


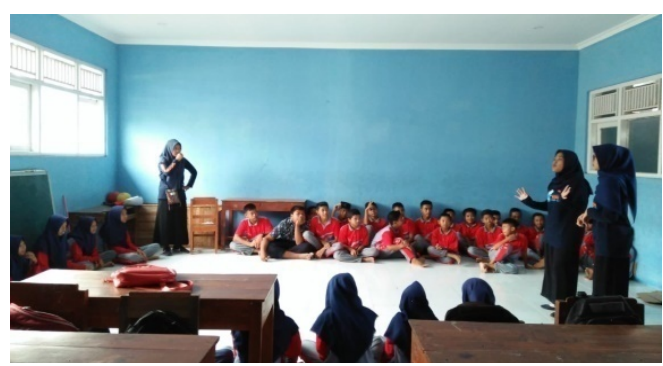

Gambar 3. Sosialisasi siswa

Ketiga, merealisasikan program 5S (Salam, Senyum, Sapa, Sopan, dan Santun) diawali dengan pembuatan poster yang ditempelkan pada dinding di setiap ruang kelas. Kemudian kami melaksanakan kegiatan rutin pagi hari dengan membentuk jadwal piket guru untuk menyambut kedatangan siswa, sehingga dapat membiasakan siswa untuk bersalaman dan mengucapkan salam kepada guru.

Kegiatan tersebut dimaksudkan agar guru dapat memberi contoh terhadap siswa terkait dengan sikap sopan santun, sehingga diharapkan siswa dapat meniru hal tersebut dan akan menjadi suatu kebiasaan. Hal ini sejalan dengan pendapat Ujiningsih (2010) yang mengemukakan bahwa pembudayaan sikap sopan santun di sekolah dapat dilakukan dengan:

1. Peran sekolah dalam membiasakan sikap sopan santun dapat dilakukan dengan memberikan contoh sikap sopan santun yang ditunjukan oleh guru,

2. Guru dapat selalu mengintegrasikan perilaku sopan santun ini dalam setiap mata pelajaran,

3. Guru agama, guru pendidikan moral pancasila dan guru BP dapat melakukan pembiasaan yang dikaitkan dalam penilaian secara efektif.

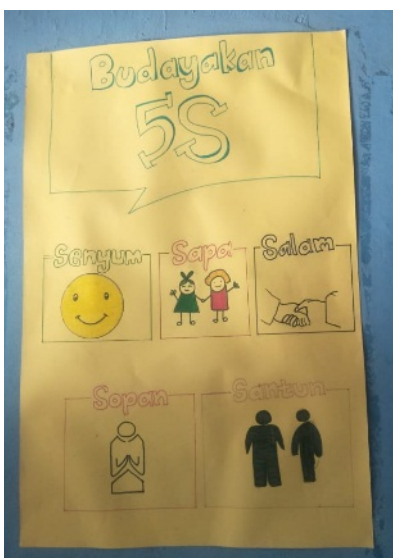

Gambar 4. Poster 5S

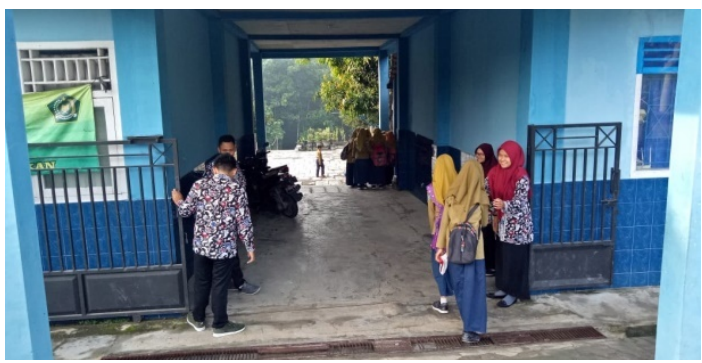

Gambar 5. Kegiatan salaman pagi

Setelah program 5S (Salam, Senyum, Sapa, Sopan, dan Santun) ini berjalan, karakter siswa mulai terbentuk. Hal ini dapat dilihat dari perubahan perilaku siswa yang semakin membaik sebagai contoh saat berjumpa dengan setiap guru siswa mulai menunjukan perilaku sopan santunnya dengan cara tersenyum, memberi salam dan berjabat tangan. Berdasarkan contoh tersebut, program 5S (Salam, Senyum, Sapa, Sopan, dan Santun) yang telah dijalankan sebagai salah satu solusi penguatan pendidikan karakter siswa dapat dikatakan cukup berpengaruh (Narimo, et al, 2018).

Program 5S (Salam, Senyum, Sapa, Sopan, dan Santun) yang diterapkan di MTs Muhammadiyah 9 Mondokan mengalami beberapa faktor penghambat program ini, antara lain: 1) terdapat beberapa siswa yang susah untuk diatur, 2) siswa kurang konsisten terdapat 
pelaksanaan program 5S, dan 3) siswa sering melanggar tata tertib. Namun, dari ketiga faktor penghambat tersebut dapat diatasi dengan beberapa faktor pendukung lainnya, seperti: 1) sikap guru yang lebih tegas terhadap pelanggaran yang dilakukan siswa, 2) guru memberikan hukuman sesuai dengan pelanggaran yang dilakukan siswa. 3) dilakukan pembiasaan sikap sopan santun baik saat kegiatan belajar mengajar (KBM) maupun diluar KBM.

Pelaksanaan program 5S (Salam, Senyum, Sapa, Sopan, dan Santun) yang telah dijalankan, diiringi dengan kegiatan evaluasi untuk meningkatkan program 5S (Salam, Senyum, Sapa, Sopan, dan Santun) agar dapat lebih baik dan semakin berpengaruh bagi penguatan pendidikan karakter siswa di sekolah terutama berkaitan dengan karakter religius, bersahabat atau komunikatif, dan peduli sosial. Adapun saran yang dapat kami berikan yaitu berupa:

1. Melakukan kegiatan berjabat tangan antara siswa dengan guru sebelum masuk kelas dan sebelum pulang sekolah.

2. Seluruh warga sekolah diharapkan dapat bertegur sapa dan tersenyum ketika bertemu dengan warga sekolah lainnya.

3. Membuat aturan tertulis terkait dengan program 5S (Salam, Senyum, Sapa, Sopan, dan Santun) maupun aturan - aturan lain disekolah.

Saran tersebut didasarkan pada penelitian (Faozah, 2014) yang menyatakan bahwa program 5S (Salam, Senyum, Sapa, Sopan, dan Santun) yang dilakukan sebagai kegiatan pengembangan diri meliputi: kegiatan rutin di sekolah, keteladanan, kegiatan spontan, dan pengkondisian. Dengan saran ini diharapkan pendidikan karakter siswa akan lebih kuat dan diharapkan karakter baik tersebut dapat dijadikan sebuah kebiasaan untuk dilakukan di luar lingkungan sekolah.

\section{Simpulan}

Penerapan program 5S (Salam, Senyum, Sapa, Sopan, dan Santun) di MTs Muhammadiyah 9 Mondokan menunjukkan hal yang positif. Dimana setelah diadakannya program 5S (Salam, Senyum, Sapa, Sopan, dan Santun) ini, para siswa cenderung mengubah perilakunya kearah yang lebih baik. Program 5S (Salam, Senyum, Sapa, Sopan, dan Santun) ini menjadi salah satu solusi dari kami untuk mengatasi permasalahan mengenai rendahnya pendidikan karakter siswa di MTs Muhammadiyah 9 Mondokan.

Dengan adanya program 5S (Salam, Senyum, Sapa, Sopan, dan Santun) ini dapat disimpulkan bahwa kegiatan berlangsung dengan efektif dan tepat sasaran, apabila seluruh warga sekolah saling memiliki sikap peduli akan pendidikan karakter. Sehingga tidak hanya siswa yang wajib berperilaku baik, tetapi guru sebagai salah satu faktor pendukung juga harus mampu menjadi suri tauladan bagi siswanya. Kegiatan 5S (Salam, Senyum, Sapa, Sopan, dan Santun) ini akan lebih baik jika dilakukan secara rutin dan berkelanjutan.

\section{Daftar Pustaka}

Budhiman, Arif. (2017). "Gerakan Penguatan Pen-didikan Karakter”. Jakarta: Kementerian Pendidikan dan Kebudayaan

Citrapujiyati. (2017). "Implementasi Grand Design Pendidikan Karakter di Sekolah Alam Sebagai Penguatan Generasi Emas 2045 (Studi Deskriptif di Sekolah Alam Ungaran)". Skripsi. Semarang: Universitas Negeri Semarang. 
Faozah,I. (2014). Pelaksanaan Pendidikan Karakter Melalui Program 5S (Senyum,Salam,Sapa, Sopan, Santun) di SD Negeri 1 Sedayu Kecamatan Sedayu Kabupaten Bantul. Yogyakarta: Universitas Negeri Yogyakarta.

Gunawan,Heri.(2012). Pendidikan Karakter Konsep dan Implementasi. Bandung: Alfabeta.

https://www.kemdikbud.go.id/

Kertajaya, H. (2010). Grow with Character: The Model Marketing. Jakarta: PT. Gramedia Pustaka Utama.

Koesoema, D. (2010). Pendidikan Karakter: Strategi Mendidik Anak di Zaman Global. Jakarta: Grasindo.

Marwanti, Endah dkk. (2018). "Implementasi Penanaman Karakter Anak dalam Syair Lagu Dolanan Anak Cublak-Cublak Suweng". Jurnal Taman Cendekia. Yogyakarta: Fakultas Keguruan dan Ilmu Pendidikan Universitas Sarjana Wiyata Taman Siswa.

Narimo, S., Maryadi, M., Fatoni, A., Anif, S., Sumardjoko, B., \& Adhantoro, M. S. (2018, November). Pancasila and Citizens Education (PKn) Learning Based on Local Culture in The Establishment of Student Characters. In Profunedu International Conference Proceeding (Vol. 1, pp. 255-260).

Prasetyo, A., \& Rivasintha, E. (2015, Juni 26). Retrieved Februari 24, 2020, from
Kompa-

siana:http;/www.edukasi.kompasiana.co $\mathrm{m}$

Rusdianti, Famila. (2015). "Implementasi Pendidikan Karakter dalam Pembelajaran Menuju Generasi Emas Indonesia". (famila rusdiantiblog.wordpress.com). Diakses hari Sabtu tanggal 25 April 2020 pukul 22.35 .

Samani, Muchlas, dan Hariyanto. 2011. Konsep dan Model Pendidikan Karakter. Bandung: Remaja Rosda Karya.

Suyanto. (2009). Urgensi Pendidikan Karakter. Jakarta: Direktorat Jendral Pendidikan Dasar Kementrian Pendidikan Nasional.

Thambu, N., Prayitno, H. J., \& Zakaria, G. A. N. (2020). Incorporating Active Learning into Moral Education to Develop Multiple Intelligences: A Qualitative Approach. Indonesian Journal on Learning and Advanced Education (IJOLAE), 3(1), 17-29.

Ujiningsih. (2010). Pembudayaan Sikap Sopan Santun di Rumah dan di Sekolah sebagai Upaya untuk Meningkatkan Karakter Siswa. Retrieved februari 27, 2020, from pustaka.ut.ac.id:http;//www.pustaka.ut.a c.id/dev25/pdfprosiding2/fkip201034.pd f. 